\section{Identification, Nomenclature, Genome Sizes, and Ploidy Levels of Liriope and Ophiopogon Taxa}

\author{
Jason D. Lattier ${ }^{1}$ and Thomas G. Ranney ${ }^{2,5}$ \\ Mountain Crop Improvement Laboratory, Department of Horticultural Science, \\ Mountain Horticultural Crops Research and Extension Center, North Carolina \\ State University, 455 Research Drive, Mills River, NC 28759-3423 \\ Paul R. Fantz ${ }^{3}$ \\ Department of Horticultural Science, North Carolina State University \\ Herbarium, Department of Plant Biology, North Carolina State University, \\ Raleigh, NC 27518 \\ Tony Avent ${ }^{4}$ \\ Plant Delights Nursery, 9241 Sauls Road, Raleigh, NC 27603
}

Additional index words. cytogenetics, DNA content, liriopogons, plant breeding, polyploidy, taxonomy

\begin{abstract}
Liriope Lour. and Ophiopogon Ker Gawl., collectively known as liriopogons, represent important evergreen groundcovers grown throughout the world for their ornamental features and medicinal qualities. As a result of the diversity of desirable traits and evidence of wide hybridization, there is considerable potential for breeding and improvement of liriopogons. However, confusion over taxonomy and proper identification and lack of information on ploidy levels and cytogenetics of individual clones and cultivars have constrained breeding efforts. Objectives of this study were to validate the identification and nomenclature and determine genome sizes and ploidy levels for an extensive reference collection of species and cultivars of liriopogons. Identification was accomplished using existing keys, nomenclature was corrected, and numerous accessions were reassigned based on morphology. Genome sizes were determined by flow cytometry. Ploidy levels for each species were confirmed by traditional cytology. Results confirmed a basic chromosome number of $x=18$ for liriopogons with aneuploidy, polyploidy, and cytochimeras found in some cases. The Liriope examined included diploids (L. graminifolia, L. longipedicellata, L. minor, and some of the $L$. platyphylla), tetraploids (L. muscari and the remaining $L$. platyphylla), and hexaploids ( $L$. exiliflora and $L$. spicata). The Ophiopogon studied included diploids (O. intermedius, $O$. jaburan, $O$. planiscapus, and $O$. umbraticola) and a tetraploid/hypotetraploid species (O. japonicus). Monoploid (1Cx) genome sizes varied by genus and species with $1 C x$ values ranging from $4.27 \mathrm{pg}$ in $L$. exiliflora to $8.15 \mathrm{pg}$ in $O$. jaburan. These results clarify nomenclature and taxonomy and provide specific information on genome sizes and ploidy levels of cultivated liriopogons. This information and associated reference collection will aid future taxonomic revisions and enhance efforts to develop new cultivars of liriopogons.
\end{abstract}

Liriopogons (most recently Ruscaceae s.l. Hutch, formerly assigned to Convallariaceae Horan., Asparagaceae Juss., Haemodoraceae Arnot, Ophiopogonaceae Kunth, and Liliaceae Juss.) (Kim et al., 2010) comprise a class of valuable evergreen groundcovers (Skinner, 1971). Liriopogons are native to China, India, Japan, Korea, the Philippines, and Vietnam with Liriope consisting of approximately eight species (Chen and Tamura, 2000a) and Ophiopogon consisting of $\approx 65$ species (Chen and Tamura, 2000b). Popularity of liriopogons is attributable, in part, to their adaptability ( $\mathrm{Li}$ et al., 2011) and versatility in the landscape, easily filling the roles of groundcovers, foundation plants, edging and massing plants, and understory plants (Fantz, 1993).

The complex taxonomy of liriopogons has been developing since the initial designation of Convallaria japonica by Thunberg (1780). or white flowers. Floral whorls are found in multiples of three (dichasia to compound dichasia to small cymes) (Fantz, 2008a). The perianth has six indistinguishable sepals and petals and six stamens. Fruits of liriopogons are blue/black and berry-like or a three-celled capsule (Fantz, 2008a).

Anatomical studies by Cutler (1992) and Rudall (2000), as well as a molecular marker investigation by Mcharo et al. (2003), concluded that similarities between Liriope and Ophiopogon were too great to warrant separation into two genera. However, morphological studies by Bailey (1929), Conran and Tamura (1998), Hume (1961), and Skinner (1971), molecular phylogenetic studies by Kim et al. (2010), and a molecular marker study by Li et al. (2011) provided evidence supporting separation of Liriope and Ophiopogon.

A recent overview of Liriope and Ophiopogon cultivated in the United States by Nesom (2010) found floral characteristics the best method of distinguishing between Liriope and Ophiopogon, supporting Fantz (2008a). Flowers belonging to Liriope are erect with corollas cupulate to rotate and free anthers with apical poricidal openings and long filaments. In contrast, flowers of Ophiopogon are nodding with corollas campanulate and connate anthers in a column, which narrow apically, dehisce longitudinally, and have subsessile filaments (Fantz, 2008a; Nesom, 2010).

In addition to the historically complex taxonomy of liriopogons, nursery practices including sexual propagation of cultivars, plant substitution, mislabeling of cultivars, and seedling invasion of stock plants have resulted in cultivar degradation within the nursery industry (Fantz, 1994). Fantz (1994) investigated 22 named species and 88 labeled cultivars of Liriope and Ophiopogon collected from nurseries and found $17 \%$ of germplasm misidentified to genus and $36 \%$ misidentified to species.

A variety of ornamental features such as flower color, inflorescence height, inflorescence branching and fasciation, fruit color, foliar variegation, and medicinal qualities such as steroidal glycosides in tubers (Cheng, et al., 2006; Wang et al., 2012; Yu et al., 1996) indicate a high potential for breeding and improvement of liriopogons. A recent study by Zhou et al. (2009) also demonstrated that hybridization between tetraploid $L$. spicata and diploid Ophiopogon may be occurring naturally in the wild, suggesting new possibilities for breeding between genera in liriopogons. However, breeding systems and cytogenetics of liriopogons are complex. Previous karyological studies have demonstrated the basic chromosome number for liriopogons to be $x=18$ (rarely $x=17$ ) with high levels of polyploidy in many species (Table 1). Also, Fukai et al. (2008) investigated ploidy level and relative genome size through flow cytometry of six species (plus cultivars) of liriopogons (Table 1). Oinuma (1946) reported polyploid forms of liriopogons exhibited increased vigor and grew over a wider geographic 
distribution than diploid forms. In addition to various ploidy levels, many studies have reported liriopogons to be uniquely tolerant of high amounts of aneuploidy (abnormal number of chromosomes) and cytochimerism (different chromosome numbers among cells in the same plant) (Table 1). Therefore, evaluating the cytogenetics of individual clones and cultivars is critical to developing a breeding strategy for liriopogons.

As a result of the wide range of ornamental traits found in liriopogons and evidence of interspecific and intergeneric hybridization, there is considerable potential for breeding and improvement of liriopogons. However, these efforts are constrained by confusion over proper taxonomy, lack of information on ploidy levels, and lack of information on cytogenetics of individual clones and cultivars. Objectives of this study were to 1) validate the identification and nomenclature; and 2) determine genome sizes and ploidy levels for an extensive reference collection of liriopogons.

\section{Materials and Methods}

Plant material. Accessions of diverse species and cultivars of liriopogons were collected from nurseries, arboreta, and various individuals (Table 2). Containerized and field specimens of liriopogons were examined in this study including L. exiliflora (L.H. Bailey) H. H. Hume, L. gigantea H. H. Hume, L. graminifolia (L.) Baker, L. longipedicellata F.T. Wang and T. Tang, L. minor (Maxim.) Makino, L. muscari (Decne.) L. H. Bailey, L. platyphylla $\mathrm{F}$. T. Wang and T. Tang, $L$. spicata (Thunb.) Lour., O. intermedius D. Don, O. jaburan (Siebold) Lodd., O. japonicus (L. f.) Ker Gawl., and O. umbraticola Hance. Multiple herbarium vouchers were collected

\footnotetext{
Received for publication 13 Nov. 2013. Accepted for publication 9 Dec. 2013.

This research was funded, in part, by the North Carolina Agricultural Research Service (NCARS), Raleigh, NC.

Use of trade names in this publication does not imply endorsement by the NCARS of products named nor criticism of similar ones not mentioned. We gratefully acknowledge Mark Weathington, JC Raulston Arboretum, Raleigh, NC; Alexander Krings, North Carolina State University Herbarium, Raleigh, NC; Tony Avent, Dennis Carey, and Jeremy Schmidt, Plant Delights Nursery, Raleigh, NC; Darrell Probst, Garden Vision Epimediums, Hubbardston, MA; Ron Rabideau, RareFind Nursery, Jackson, NJ; Paul Jones, Sarah P. Duke Gardens, Durham, NC; and Nathan Lynch and Kim Shearer, Mountain Crop Improvement Lab, Mills River, NC, for their cooperation, technical assistance, and contributions of plant material for this study.

From a thesis submitted by J.D.L. in partial fulfillment of the requirements for the MS degree.

${ }^{1}$ Graduate Research Assistant.

${ }^{2}$ Professor Emeritus and Research Taxonomist.

${ }^{3}$ Professor.

${ }^{4}$ Owner of Plant Delights Nursery and founder of Juniper Level Botanical Gardens.

${ }^{5}$ To whom reprint requests should be addressed; e-mail tom_ranney@ncsu.edu.
}

for nearly all taxa and identified based on previous descriptions and available keys for liriopogons (Broussard, 2007; Chen and Tamura, 2000a, 2000b; Cutler, 1992; Fantz, 2008a, 2008b, 2009; Hasegawa, 1968; Liu et al., 2007; Nesom, 2010; Tamura, 1990; Tanaka, 2000, 2001a, 2001b, 2001c; Zhang, 1998). The primary collection will be deposited at the North Carolina State University Herbarium, Department of Plant and Microbial Biology, Raleigh, and the Herbarium of the U.S. National Arboretum.

Survey of genome sizes and ploidy levels. Genome sizes and ploidy levels were determined by traditional cytology in combination with flow cytometry. To prepare samples for flow cytometry, leaf tips $\left(\approx 1 \mathrm{~cm}^{2}\right)$ from expanded leaves of each taxa were placed in petri dishes containing $500 \mu \mathrm{L}$ of nuclei extraction buffer (CyStain ultraviolet Precise P Nuclei Extraction Buffer ${ }^{\circledR}$; Partec, Münster, Germany) and chopped finely with a razor blade until completely incorporated into buffer. Resulting solutions were pipetted through CellTrics ${ }^{\mathrm{TM}}$ (Partec) disposable filters with a pore size of $50 \mu \mathrm{m}$. Then, $2 \mathrm{~mL}$ of a nucleotide staining buffer solution combined with $6 \mu \mathrm{L}$ RNase A and $12 \mu \mathrm{L}$ propidium iodide (CyStain PI absolute P; Partec) was added to the filtered solutions. Samples were refrigerated $\left(4{ }^{\circ} \mathrm{C}\right)$ and incubated for over $30 \mathrm{~min}$, and the resulting stained nuclei were analyzed with a flow cytometer (Partec PA II; Partec) with counts exceeding a minimum of 3000 cells per analysis.

Mean fluorescence for each sample was compared with an internal standard of known genome size (Pisum sativum L. 'Ctirad', 2C $\mathrm{DNA}=8.76 \mathrm{pg}$ ), and holoploid, $2 \mathrm{C}$ genome size (i.e., DNA content of entire nonreplicated chromosome compliment irrespective of ploidy) was calculated as $2 \mathrm{C}=\mathrm{DNA}$ content of standard $\times$ (mean fluorescence of sample/mean fluorescence of standard). Monoploid genome sizes $(1 \mathrm{Cx}=\mathrm{DNA}$ content of the non-replicated base set of chromosomes, $1 x)$ were calculated for each sample as (2C genome size/ploidy level). Monoploid genome sizes were subjected to analysis of variance by genus and species, and means were separated using Fisher's least significant difference (Proc GLM; SAS Version 9.2; SAS Inst., Cary, NC).

Chromosome counts were performed on selected species of liriopogons to confirm ploidy levels and to allow for calibration of ploidy level with genome size. A root squash technique was used that allowed for direct counting of chromosomes. Actively growing root tips were collected and placed in freshly made vials of pre-fixative solution (2 $\mathrm{mm} 8$ hydroxyquinoline $+70 \mathrm{mg} \cdot \mathrm{L}^{-1}$ cyclohexamide) at room temperature $\left(22^{\circ} \mathrm{C}\right)$. After remaining in the dark for $3 \mathrm{~h}$, all vials were moved into a dark refrigerator at $\approx 4{ }^{\circ} \mathrm{C}$ for $3 \mathrm{~h}$, yielding a total pre-fixative treatment of $6 \mathrm{~h}$. Root tips were then rinsed with distilled water and transferred to a freshly made fixative of $1: 3$ propionic acid to $95 \%$ ethanol and left at room temperature overnight. The following day, a 1:3 hydrolysis solution of
$12 \mathrm{M} \mathrm{HCl}$ to $95 \%$ ethanol was made for the root squash procedure.

For each root squash, a fresh root was removed from the fixative and hydrolyzed for 12 to $20 \mathrm{~s}$ before being moved to a clean slide. The root tip was excised using a dissecting microscope (StereoZoom 6 Photo; Leica Microsystems $\mathrm{GmbH}$, Wetzlar, Germany) and placed on a separate, clean slide with a drop of modified carbol fuchsin stain (Carr and Walker, 1961; Kao, 1975). A coverslip was placed over the droplet of stain containing the excised root tip and a clean sheet of bibulous paper was placed over the slide while gently applying pressure with a pencil eraser. An average of 10 highly resolved cells per specimen were used to visualize the total number of chromosomes using a light microscope (Eclipse 80i, Nikon, Melville, NY). Extended depth of field was achieved by layered images containing multiple focal points using Photoshop CS4 (Adobe Systems, San Jose, CA).

\section{Results and Discussion}

Liriope exiliflora. The relatively large $2 \mathrm{C}$ genome size of $L$. exiliflora ranged from 24.89 to $26.18 \mathrm{pg}$ (Table 2). This range of genome size fell between that of $L$. gigantea and L. muscari. Cytology determined $L$. exiliflora (MCI 2011-100) to be a hexaploid at $2 n=6 x=108$ (Fig. 1A). Possibly, former cytological studies included L. exiliflora under a different synonym, although no former studies were found to compare with our findings. Our results lend evidence for the treatment of $L$. exiliflora as a separate species in agreement with Fantz (2008b) and in contrast to claims of synonymy with L. muscari by Nesom (2010). Cultivars Silver Dragon and Quail Garden were acquired as $L$. spicata and were reassigned $L$. exiliflora according to Fantz (2008b). However, further investigation into a close relationship between $L$. exiliflora and $L$. spicata may be warranted based on their similar morphology, ploidy, and monoploid genome size values (Table 3).

Liriope gigantea. Often confused with $L$. muscari, four cultivars of L. gigantea including 'Green Giant', 'Evergreen Giant', 'Lynn Lowrey', and 'Merton Jacobs' were found to have larger $2 \mathrm{C}$ genome sizes (26.23 to $28.86 \mathrm{pg}$ ) than any L. muscari (17.64 to $21.53 \mathrm{pg}$ ) included in this study (Table 2). Cytology determined L. gigantea (MCI 2011099 ) to be a tetraploid at $2 n=4 x=72$. Monoploid genome sizes were significantly larger in L. gigantea $(6.92 \mathrm{pg})$ than L. muscari $(4.76 \mathrm{pg})$. Former cytological studies possibly included $L$. gigantea under a different synonym, although no former studies were found to compare with our findings. Cultivars Green Giant, Evergreen Giant, and Lynn Lowrey were acquired as L. muscari. However, these cultivars were reassigned according to Fantz (2008b) and Nesom (2010) and based on similarity of genome size and ploidy level with known L. gigantea. 
Table 1. Previous cytological and cytometric analyses of liriopogons.

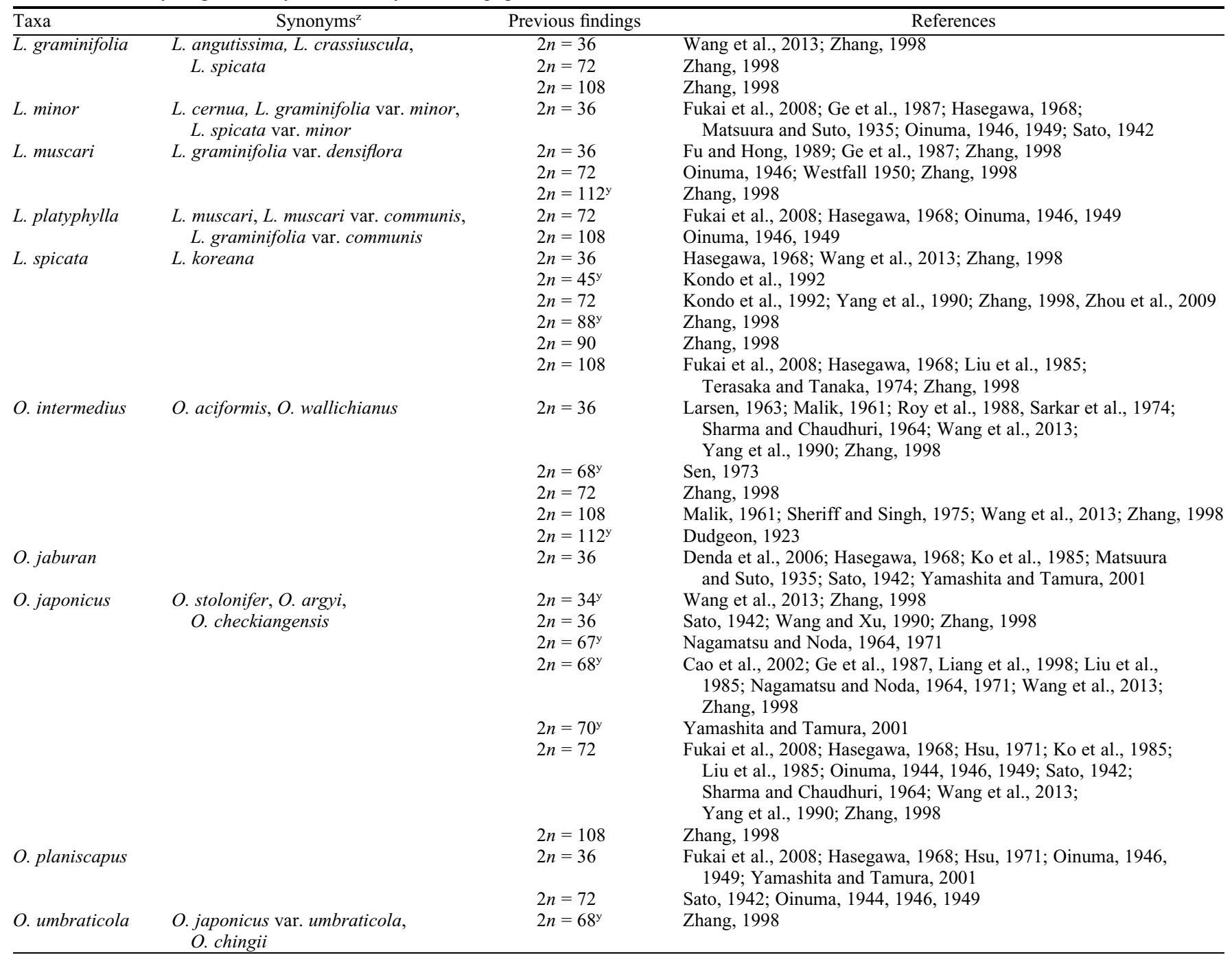

${ }^{\mathrm{z}}$ Synonyms for taxa obtained from cited studies, from Tropicos ${ }^{\circledR}$, Missouri Botanic Garden, or from common misidentifications in the U.S. nursery industry. yPossible hypoploid or hyperploid specimen based on basic chromosome number of $x=18$.

Liriope graminifolia. This grass-like species of Liriope is characterized by thin, soft leaves with heavy flowering inflorescences hidden among or just topping the leaves (Chen and Tamura, 2000a). Liriope matching this description in the present study included 'Porcupine', a clone (MCI 2010-063) earlyblooming in April in North Carolina, and a wild-collected clone (MCI 2012-098) from Sichuan, China (D. Probst, personal communication). Although the leaf form was similar for all specimens in this group, inflorescence length varied. Some specimens exhibited flowers blooming well above the foliage (initially thought to be a narrow leaf form of L. platyphylla) and some specimens exhibited flowers blooming among the foliage. The $2 \mathrm{C}$ genome size for L. graminifolia ranged from 10.44 to $11.08 \mathrm{pg}$ (Table 2) and cytology determined L. graminifolia Clone B (MCI 2012-098) and L. graminifolia 'Porcupine' (MCI 2010-056) to be a diploids with $2 n=2 x=$ 36. Monoploid genome sizes for L. graminifolia $(5.41 \mathrm{pg})$ did not significantly differ from the morphologically similar diploid, L. minor (5.60 pg) (Table 3$)$. In addition to diploids, previous research has reported L. graminifolia to be tetraploid $(2 n=72)$ and hexaploid $(2 n=108)$ (Table 1$)$. Liriope graminifolia Clone B was acquired as $O$. intermedius and reassigned according to Chen and Tamura (2000a) and Nesom (2010).

Liriope longipedicellata. As the name suggests, the most identifiable feature of $L$. longipedicellata is its extended pedicels (Chen and Tamura, 2000a), giving the inflorescence a bottle brush appearance. Otherwise, the species resembles the narrow-leaved $L$. graminifolia, and similar genome sizes and ploidy levels further suggest a close relationship. Liriope longipedicellata 'Grape Fizz' was found to have a $2 \mathrm{C}$ genome size of $11.10 \mathrm{pg}$ and the wild-collected L. longipedicellata (MCI 2012-092) was found to have a $2 \mathrm{C}$ genome size $12.31 \mathrm{pg}$, just outside the observed range for L. graminifolia (Table 2). Cytology demonstrated $L$. longipedicellata (MCI 2012-092) to be a diploid with $2 n=$ $2 x=36$. Monoploid genome sizes for $L$. longipedicellata $(5.86 \mathrm{pg}$ ) were found to be similar to $L$. minor $(5.60 \mathrm{pg}$ ) but larger than $L$. graminifolia $(5.41 \mathrm{pg})$, all being narrow leaf liriopes (Table 3). Although it is possible that former cytological studies included $L$. longipedicellata under a different synonym, no former studies were found to compare with our findings. Liriope longipedicellata 'Grape Fizz' was acquired as $O$. intermedius 'Grape Fizz' and was reassigned according to Chen and Tamura (2000a)

Liriope minor. This species represents a spreading, dwarf Liriope with narrow leaves occasionally blotched yellow with leaf and inflorescence length less than $20 \mathrm{~cm}$ (Chen and Tamura, 2000a; Fantz, 2008b). Both specimens in this study exhibited yellow blotched variegation. Cytometry revealed 2C genome sizes from 11.08 to $11.31 \mathrm{pg}$ (Table 2), placing it in a similar range as $L$. graminifolia and L. longipedicellata. Further cytological examination of both specimens revealed $L$. minor to be a diploid $2 n=2 x=36$ (Fig. 1B), concurring with previous studies reporting $L$. minor also to be a diploid (Table 1 ). The similar appearance, genome sizes, and ploidy levels revealed in this study suggest a close relationship among $L$. graminifolia, $L$. longipedicellata, and L. minor with L. minor 
Table 2. Genome sizes and estimated ploidy levels of cultivated Liriope and Ophiopogon.

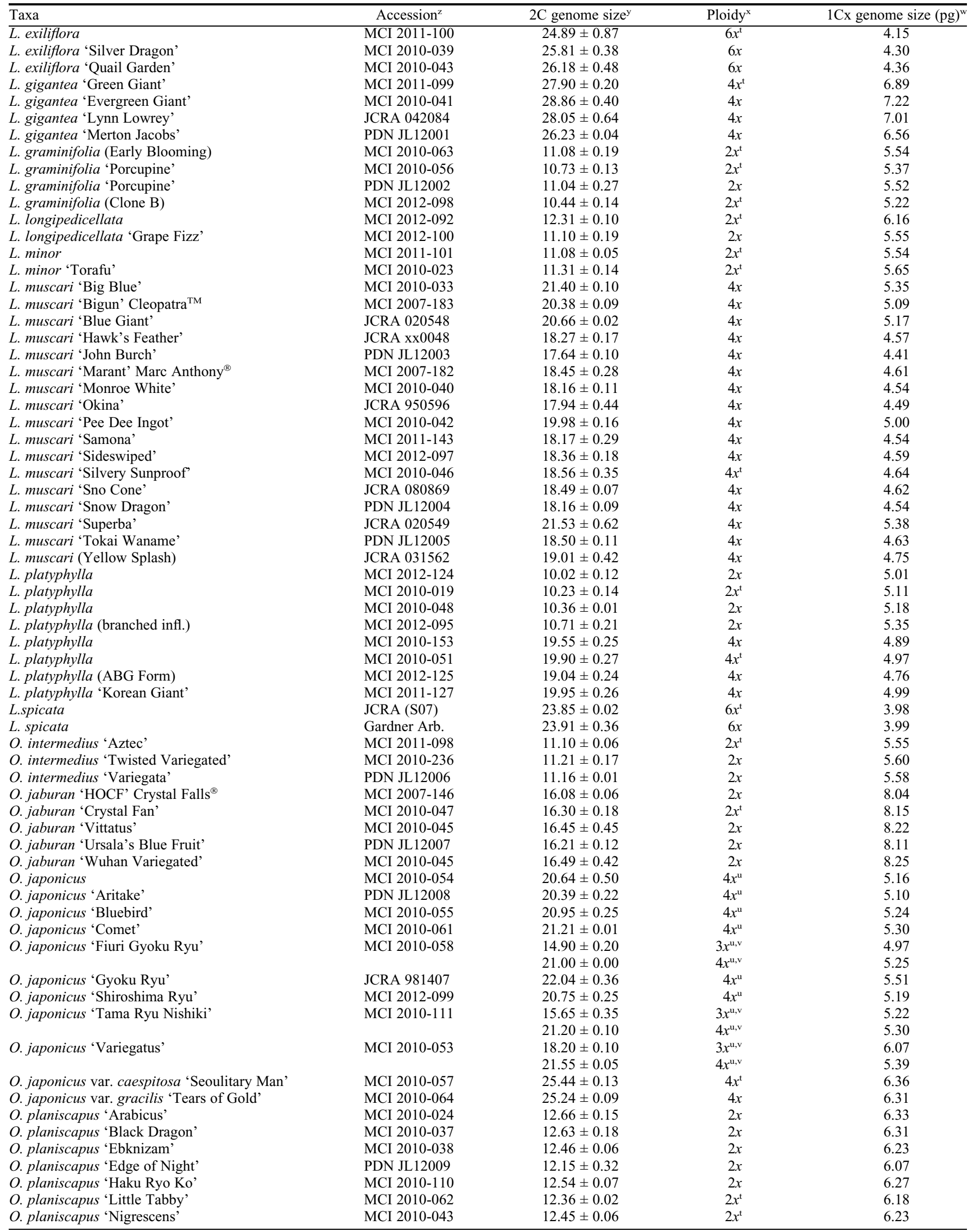

(Continued on next page) 
Table 2. (Continued) Genome sizes and estimated ploidy levels of cultivated Liriope and Ophiopogon.

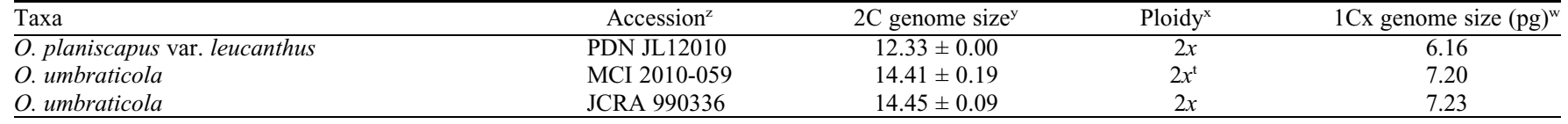

${ }^{2}$ JCRA = J.C. Raulston Arboretum, Raleigh, NC; PDN = Plant Delights Nursery, Raleigh, NC; MCI = Mountain Crop Improvement Laboratory, North Carolina State University, Mills River, NC.; Gardner Arb. = Gardner Arboretum, North Carolina State University, Raleigh, NC.

${ }^{\mathrm{y}}$ Holoploid genome sizes were determined using propidium iodide as the flourochrome stain. Values are $\mathrm{x} \pm \operatorname{SEM}, \mathrm{n}=2-3$.

xPloidy levels, $2 x=$ diploid; $3 x=$ triploid; $4 x=$ tetraploid; $5 x=$ pentaploid; $6 x=$ hexaploids.

${ }^{\mathrm{w}} 1 \mathrm{Cx}$ values were calculated as $2 \mathrm{C}$ value/ploidy level.

${ }^{\mathrm{v}}$ Cytochimera of multiple ploidy levels (mixoploid) confirmed by flow cytometry.

"Possible hypoploid specimens based on high variability in attempted chromosome counts.

'Ploidy levels confirmed by cytology.

having the smallest stature. Liriope minor 'Torafu' was acquired as L. muscari 'Torafu' and reassigned according to Chen and Tamura (2000a) and Fantz (2008b).

Liriope muscari. Seventeen cultivars of $L$. muscari ranged in 2C genome size from 17.64 to $21.53 \mathrm{pg}$ (Table 2). Cultivars with large genome sizes such as 'Superba' (21.53 pg) and 'Big Blue' (21.40 pg) were observed to have the most vigor (fastest growth and largest clumps) and heaviest fruit set of all L. muscari tested (J. Lattier, personal observation). A possible explanation for this is suggested in an earlier study by Westfall (1950) where many L. muscari studied were found to be sterile or only partially fertile as a result of high levels of aneuploidy. In addition, hypotetraploid lines were found to have high levels of variation in inflorescence morphology, leaf width, vigor, and fertility (Westfall, 1950). Our results indicate a similar trend with all green leaf forms (except for the white-flowering 'Monroe White') having a $2 \mathrm{C}$ genome size greater than $20 \mathrm{pg}$ and all variegated forms or forms with abnormal inflorescences having a $2 \mathrm{C}$ genome size less than $20 \mathrm{pg}$ (Table 2). Monoploid genome sizes for $L$. muscari (4.76 pg) indicated a unique genome size within Liriope, with the exception of L. platyphylla which had a similar genome size of (5.03 pg) (Table 3). Cytology of 'Silvery Sunproof' confirmed it to be a tetraploid with $2 n=4 x=72$, contrasting with one report of a diploid at $2 n=36$ and one report of a rare specimen at $2 n=112$ for L. muscari (Table 1).

Liriope platyphylla. Recent taxonomic studies including Nesom (2010) have treated the broad-leaved L. platyphylla as synonymous with $L$. muscari, or a variety of $L$. muscari, based on the merger of these two species by Hara (1984) and Hsu and Li (1981). Also, molecular studies have indicated a close relationship between $L$. muscari and L. platyphylla (Wu et al., 1998). However, the combination of the two species has led to much confusion in interpretation of previous literature and identification of this distinctive Liriope (Fantz, 2008b). Samples in the present study were distinguishable easily from $L$. muscari in agreement with Fantz (2008b) based on their wide, leathery leaves and elongated inflorescence extending well above the foliage. Eight specimens were tested including one with a branching rachis (MCI
2012-095), one particularly large form from the Atlanta Botanical Garden with a nearly 4foot tall inflorescence (MCI 2012-125) and one cultivar (Korean Giant). Flow cytometry revealed a ploidy series including four specimens with genome sizes from 10.02 to $10.71 \mathrm{pg}$ and four specimens with $2 \mathrm{C}$ genome sizes from 19.04 to $19.95 \mathrm{pg}$ (Table 2). Although morphologically distinct, $1 \mathrm{Cx}$ values of L. platyphylla (5.03 pg) were similar to L. muscari (4.76 pg) (Table 3). There was a general trend of the tetraploid specimens exhibiting more vigorous growth and larger overall sizes. A further cytological study was conducted finding MCI 2010-019 to be a diploid with $2 n=2 x=36$, whereas MCI 2010-051 was found to be a tetraploid with $2 n=4 x=72$. The only other reported ploidy level for L. platyphylla was found to be hexaploid with $2 n=108$, although it is likely that cytological studies have been conducted under different synonyms (Table 1).

Liriope spicata. The relatively large $2 \mathrm{C}$ genome size of L. spicata ranged from 23.85 to $23.91 \mathrm{pg}$ but was slightly lower than L. exiliflora. Monoploid genome sizes for L. spicata $(3.99 \mathrm{pg})$ and L. exiliflora $(4.27 \mathrm{pg})$ were not significantly different (Table 3 ). Cytology determined L. spicata (JCRA S07) to be a hexaploid at $2 n=6 x=108$. In addition to hexaploids, previous research has reported many different ploidy levels for $L$. spicata including $(2 n=45,72,88,90)$ (Table 1$)$. This species represents a diminutive Liriope, which spreads aggressively by rhizomes (Fantz, 2008b). This species is often confused in the trade with the larger $L$. exiliflora, which clumps for several years before spreading, although less aggressively than L. spicata (Fantz, 2008b).

Ophiopogon intermedius. Cytometric analysis of 'Aztec', 'Twisted Variegated', and two samples of 'Variegatus' showed a range of $2 \mathrm{C}$ genome sizes from 11.10 to $11.21 \mathrm{pg}$ (Table 2). Cytology determined 'Aztec' to be a diploid with $2 n=2 x=36$. However, previous studies have reported wide ranges of ploidy levels for $O$. intermedius at $2 n=36,68,72,108$, and 112 (Table 1). Ophiopogon intermedius 'Aztec' was acquired as L. spicata 'Aztec' and was reassigned in agreement with Fantz (2009) and Nesom (2010). Ophiopogon intermedius 'Aztec' is misidentified commonly in the trade as L. muscari or O. jaburan (Fantz, 2009).
Ophiopogon jaburan. Cytometry of $O$. jaburan 'HOCF', 'Crystal Fan', 'Vittatus', 'Ursala's Blue Fruit', and 'Wuhan Variegated' found a range of $2 \mathrm{C}$ genome sizes from 16.08 to $16.49 \mathrm{pg}$ (Table 2). Cytology of 'Crystal Fan' documented it to be a diploid with $2 n=2 x=36$. Interestingly, $O$. jaburan had a significantly larger monoploid genome size $(8.15 \mathrm{pg})$ than all other liriopogons (Table 3). Compared with other liriopogons in this study, $O$. jaburan had a surprisingly consistent cytological record of existing
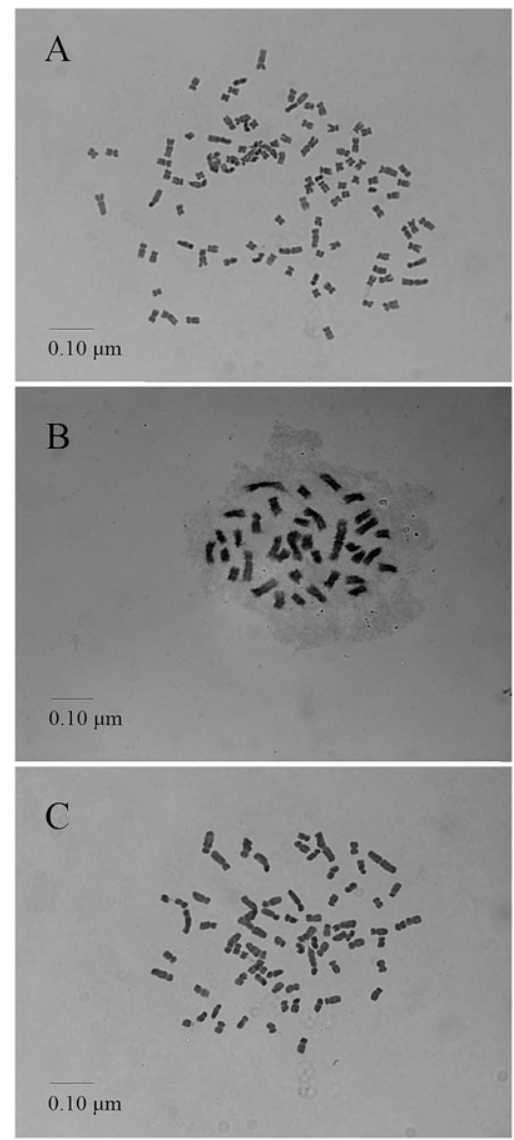

Fig. 1. Representative photomicrographs of metaphase chromosomes from root tip cell of liriopogons viewed at $\times 1000$ : (A) Liriope exiliflora $(2 n=6 x=108)$; (B) L. minor $(2 n=$ $2 x=36$ ); (C) Ophiopogon japonicus var. caespitosa 'Seoulitary Man' $(2 n=4 x=72)$. 
Table 3. Monoploid (1Cx) genome sizes of cultivated Liriope and Ophiopogon determined using flow cytometry and grouped by genus and species.

\begin{tabular}{|c|c|c|c|}
\hline Genus & $1 \mathrm{Cx}(\mathrm{pg})$ & Species & $1 \mathrm{Cx}(\mathrm{pg})$ \\
\hline Liriope & $5.10 \pm 0.12 \mathrm{a}^{\mathrm{z}}$ & L. exiliflora & $4.27 \pm 0.06 \mathrm{a}^{\mathrm{z}}$ \\
\hline \multirow[t]{13}{*}{ Ophiopogon } & $6.27 \pm 0.19 \mathrm{~b}$ & L. gigantea & $6.92 \pm 0.14 \mathrm{~g}$ \\
\hline & & L. graminifolia & $5.41 \pm 0.07 \mathrm{~d}$ \\
\hline & & L. longipedicellata & $5.86 \pm 0.04 \mathrm{e}$ \\
\hline & & L. minor & $5.60 \pm 0.06 \mathrm{de}$ \\
\hline & & L. muscari & $4.76 \pm 0.08 \mathrm{~b}$ \\
\hline & & L. platyphylla & $5.03 \pm 0.06 b c$ \\
\hline & & L. spicata & $3.99 \pm 0.01 \mathrm{a}$ \\
\hline & & O. intermedius & $5.58 \pm 0.01 \mathrm{de}$ \\
\hline & & O. jaburan & $8.15 \pm 0.04 \mathrm{~h}$ \\
\hline & & O. japonicus & $5.27 \pm 0.04 \mathrm{~cd}$ \\
\hline & & O. japonicus var. ${ }^{\mathrm{y}}$ & $6.34 \pm 0.03 \mathrm{f}$ \\
\hline & & O. planiscapus & $6.22 \pm 0.03 \mathrm{f}$ \\
\hline & & O. umbraticola & $7.22 \pm 0.02 \mathrm{~g}$ \\
\hline
\end{tabular}

${ }^{\mathrm{z}}$ Values represent means \pm SEM. Means separated within columns using Fisher's least significant difference with $P<0.05$.

${ }^{\mathrm{y}}$ Includes the morphologically unique varieties $O$. japonicus var. caespitosa and $O$. japonicus var. gracilis.

primarily as a diploid at $2 n=36$ (Table 1 ) in agreement with our findings.

Ophiopogon japonicus. Cytometry of 11 taxa of $O$. japonicus showed two distinct ranges of $2 \mathrm{C}$ genome sizes. The majority of O. japonicus samples ranged from 20.39 to $22.04 \mathrm{pg}$, whereas 'Tears of Gold' and 'Seoulitary Man' ranged from 25.24 to $25.44 \mathrm{pg}$ (Table 2). These two clones represented varieties with larger overall form and were found to have a significantly different $1 \mathrm{Cx}$ value $(6.34 \mathrm{pg})$ than the other $O$. japonicus $(5.27 \mathrm{pg})$ (Table 3). Originally thought to be a hyperploid specimen, cytology confirmed 'Seoulitary Man' to be a tetraploid with $2 n=$ $4 x=72$ (Fig. 1C). Ploidy analysis remains inconclusive for other $O$. japonicus, likely as a result of high levels of hypotetraploidy as reported in previous studies (Table 1). A wide range of ploidy levels has been previously reported for $O$. japonicus including $2 n=36$, 67, 68, 70, and 72 (Table 1). In the present study, three samples examined using flow cytometry ('Fiuri Gyoku Ryu', 'Tama Ryu Nishiki', and 'Variegatus') yielded multiple fluorescence peaks with hypotetraploid peaks being associated with the variegated tissue. This phenomenon was only observed in variegated cultivars of $O$. japonicus. Wang and $\mathrm{Xu}(1990)$ also found cytochimeras in O. japonicus with diploid, triploid, and tetraploid cells existing in the same plant.

Ophiopogon planiscapus. Of the eight taxa of $O$. planiscapus tested, 2C genome sizes ranged from 12.15 to $12.66 \mathrm{pg}$ (Table $2)$. With the exception of the few large varieties of $O$. japonicus included in this study, O. planiscapus had a significantly different $1 \mathrm{Cx}$ value $(6.22 \mathrm{pg})$ among the liriopogons. Cytology of the cultivar Nigrescens showed it to be $2 n=2 x=36$. The majority of former cytological studies of $O$. planiscapus agrees with the present study; however, tetraploid forms $(2 n=72)$ have been reported (Table 1).

Ophiopogon umbraticola. Often mislabeled as $O$. chingii in the nursery industry (J. Lattier, personal observation), two samples of O. umbraticola (MCI 2010-059, JCRA 990336) had 2C genome sizes ranging from 14.41 to $14.45 \mathrm{pg}$, which represents a unique range of genome size compared with all liriopogons tested in the present study (Table 2). Further cytological study of O. umbraticola (MCI 2010-059) revealed it to be a diploid at $2 n=2 x=36$ in contrast to one previous report of hypotetraploidy, $2 n=$ 68 (Table 1). Monoploid genome sizes for O. umbraticola $(7.22 \mathrm{pg})$ were significantly different from the rest of the Ophiopogon (Table 3). Ophiopogon umbraticola (MCI 2010-059) was acquired as $O$. chingii and reassigned according to Chen and Tamura (2000b) and Tanaka (2001a).

Information on ploidy levels and genome sizes can have important implications for plant breeding (Ranney, 2006). Intraploid hybridizations are often more productive than interploid hybridizations, although interploid hybridizations can often provide an avenue for developing seedless cultivars. Also, compatibility of genomes/chromosomes is necessary for meiosis to function properly, and similarity in genome sizes can be indicative of close phylogenetic relationships and genome compatibility within taxonomic groups. Development of fertile hybrids may be improved when breeding among plants with similar genome sizes and ploidy levels (Parris et al., 2010).

This study details the development and documentation of an extensive collection of both living specimens and herbarium vouchers for liriopogons. Several source names were misidentified to genus, and many were misidentified to species like in a previous report by Fantz (1994). Genome sizes and ploidy levels were determined for all taxa in this study. Results confirm the basic chromosome number of $x=18$ for liriopogons with aneuploidy, polyploidy, and cytochimeras found in some cases. Based on our sampling, Liriope examined fit into three ploidy groups with one exception of a ploidy series of L. platyphylla. The diploid group consisted of L. graminifolia, L. longipedicellata, L. minor, and some L. platyphylla. The tetraploid group consisted of L. muscari and the remaining L. platyphylla. The hexaploid group consisted of L. exiliflora and L. spicata. Although controversy surrounds the maintenance of $L$. gigantea, L. graminifolia, and L. exiliflora as separate species, differences in $1 \mathrm{Cx}$ genome size lends evidence for maintaining L. gigantea as a distinct species separate from $L$. muscari and as suggested by Fantz (2008b) and Nesom (2010), L. muscari as a distinct species separate from $L$. exiliflora or $L$. spicata as suggested by Fantz (2008b), and L. graminifolia as a distinct species separate from L. spicata or L. exiliflora as suggested by Chen and Tamura (2000a) and Nesom (2010). Ophiopogon included in this study formed two ploidy groups. The diploid group included $O$. intermedius, $O$. jaburan, $O$. planiscapus, and O. umbraticola. The tetraploid/hypotetraploid group consisted of $O$. japonicus. Monoploid genome sizes varied based on genus and species and ranged from $4.27 \mathrm{pg}$ in $L$. exiliflora to $8.15 \mathrm{pg}$ in $O$. jaburan (Table 3 ). Based on the taxa sampled, mean $1 \mathrm{Cx}$ genome sizes were smaller for Liriope $(5.10 \mathrm{pg})$ than for Ophiopogon (6.27 pg) (Table 3). Although breeding efforts in the past have been limited by confusion over proper identification of germplasm and lack of information on ploidy levels and cytogenetics of available clones and cultivars, the reference collection established in this study will aid future revisions as well as assist in the development of breeding strategies for liriopogons.

\section{Literature Cited}

Bailey, L.H. 1929. The case of Ophiopogon and Liriope. Gentes Herb. 2:1-37.

Broussard, M.C. 2007. A horticultural study of Liriope and Ophiopogon: Nomenclature, morphology, and culture. $\mathrm{PhD}$ diss.,, Louisiana State University, Baton Rouge, LA.

Cao, Y., D.-r. Qiao, Y.-x. Li, H.-x. Xing, and Y. Jiang. 2002. Karyotypical analysis of erective and creepy Ophiopogon japonicus in Mianyang of Sichuan. Journal of Sichuan University 39:345-348 (Natural Science Edition.

Carr, D.H. and J.E. Walker. 1961. Carbol fuchsin as a stain for human chromosomes. Stain Technol. 36:233-236.

Chen, S.C. and M.N. Tamura. 2000a. Liriope, p. 250251. In: Wu, Z.Y. and P. H. Raven (eds.). Flora of China 24. Science Press, Beijing, and Missouri Botanical Garden Press, St. Louis, MO.

Chen, S.C. and M.N. Tamura. 2000b. Ophiopogon, p. 250-251. In: Wu, Z.Y. and P. H. Raven (eds.). Flora of China 24. Science Press, Beijing, and Missouri Botanical Garden Press, St. Louis, MO.

Cheng, Z.H., T. Wu, Y.L. Guo, B.Y. Yu, and L.S. Xu. 2006. Two new steroidal glycosides from Liriope muscari. Chin. Chem. Lett. 17:31-34.

Conran, J.G. and M.N. Tamura. 1998. Convallariaceae, p. 186-198. In: Kubitzki, K. (ed.). The families and genera of vascular plants. Springer, Berlin, Germany.

Cutler, D.F. 1992. Vegetative anatomy of Ophiopogoneae (Convallariaceae). Bot. J. Linn. Soc. 110:385-419.

Denda, T., K. Nakamura, and M. Yokota. 2006. Karyotype of Ophiopogon reversus (Convallariaceae) from Taiwan and the southern Ryukyus. Taiwania 51:117-122.

Dudgeon, W. 1923. Section of botany. Proc. of the 9th Indian Science Congress. Proc. Asiat. Soc. Bengal 18:95-124. 
Fantz, P.R. 1993. Taxonomic problems in cultivated liriopogons. HortTechnology 3:146-149.

Fantz, P.R. 1994. Taxonomic problems in cultivated liriopogons. HortTechnology 3:146-150.

Fantz, P.R. 2008a. Macrophytogeography of cultivated liriopogons and genera delineation. HortTechnology 18:334-342.

Fantz, P.R. 2008b. Species of Liriope cultivated in the southeastern United States. HortTechnology 18:343-348.

Fantz, P.R. 2009. Names and species of Ophiopogon cultivated in the southeastern United States. HortTechnology 19:385-394.

Fu, C.X. and D.Y. Hong. 1989. Cytotaxonomical studies on Liliaceae (S.1.); (2) Report on chromosome numbers and karyotypes of 8 species of 8 genera from Zhejiang, China. Acta Phytotaxon. Sin. 27:439-450.

Fukai, S., T. Shimomura, and T. Kondo. 2008. Convallariaceae ground cover plants native to Asia. ISHS Acta Horticulturae 769: XXVII International Horticultural Congress-IHC2006: International Symposium on Asian plants with unique horticultural potential.

Ge, C., Y. Li, and Y. Zhou. 1987. Observations on the chromosome numbers of medicinal plants plants of Shandong province. Acta Botanica Yunnanica 9:333-338.

Hara, H. 1984. Comments on the East Asiatic plants (13). J. Jap. Bot. 59:33-41.

Hasegawa, K.M. 1968. Cytotaxonomic studies on the genera Liriope and Ophiopogon in Japan. J. Japanese Bot. 43:141-155.

Hsu, C.C. 1971. Preliminary chromosome studies on the vascular plants of Taiwan (IV). Counts and some systematic notes on some monocotyledons. Taiwania 16:123-136.

Hsu, P.S. and L.C. Li. 1981. Critical notes on the classification of the Liriope muscari complex. Acta Phytotax. Sini. 19:456-461.

Hume, H.H. 1961. The Ophiopogon-Liriope complex. Baileya 9:135-158.

Kao, K.N. 1975. A nuclear staining method for protoplasts, p. 60-64. In: Gamborg, O.L. and L.Z. Wetter (eds.). Plant tissue culture methods. L.R. National Research Council of Canada, Praire Regional Laboratory, Saskatoon, Saskatchewan, Canada.

Kim, J.-H., D.-K. Kim, F. Forest, M.F. Fay, and M.W. Chase. 2010. Molecular phylogenetics of Ruscaceae sensu lato and related families (Asparagales) based on plastid and nuclear DNA sequences. Ann. Bot. (Lond.) 106:775790.

Ko, S.C., Y.O. Kim, and Y.S. Kim. 1985. A cytotaxonomical study on the tribe Ophiopogoneae in Korea. Kor. J. Plant Tax. 15:111125.

Kondo, K., K. Taniguchi, R. Tanaka, and Z. Gu. 1992. Karyomorphological studies in Chinese plant-species involving the Japanese floristic elements, I. American Camellia Yearbook. p. 131-156.

Larsen, K. 1963. Studies in the flora of Thailand (IV). Counts and some systematic notes on some monocotyledons. Taiwania 16:123-136.

Li, G., W.-H. Ra, J.-W. Park, S.-W. Kwon, J.-H. Lee, C.-B. Park, and Y.-J. Park. 2011. Developing EST-SSR markers to study molecular diversity in Liriope and Ophiopogon. Biochem. Syst. Ecol. 39:241-252.
Liang, G., M. Yang, and Y. Yan. 1998. Karyotypical analysis of Ophiopogon japonicus in Sichuan. Journal of Southwest Agricultural University 20:307-310.

Liu, W.-Q., J.-H. Jin, and W.-B. Liao. 2007. Ophiopogon acerobracteatus (Convallariaceae), a new species from southern China. Ann. Bot. Fenn. 44:492-494.

Liu, Y., S.A. Zhang, P.S. Hsu, and L.C. Li. 1985 Chromsome numbers of several cultivated plants from Shanghai. J. Wuhan Bot. Res. 3:225-228 (Wuhan Zhiwuxue Yanjou).

Malik, C.P. 1961. Chromosome number in some Indian Angiosperms: Monocotyledons. Sci. Cult. 27:197-198.

Matsuura, H. and T. Suto. 1935. Contributions to the idiogram study in phanerogamous plants. I. J. Fac. Sci. Hokkaido Imp. Univ., Ser. 5. Bot. 5:33-75.

Mcharo, M., E. Bush, D. LaBonte, C. Broussard, and L. Urbatsch. 2003. Molecular and morphological investigation of ornamental liriopogons. J. Amer. Soc. Hort. Sci. 128: 575-577.

Nagamatsu, T. and S. Noda. 1964. Chromsome constitution of Ophiopogon japonicus. Bull. Osaka Gakuin Univ 3:185-190 [in Japanese with English summary ].

Nagamatsu, T. and S. Noda. 1971. Balanced hypotetraploids in Ophiopogon japonicus and O. ohwii. Cytologia (Tokyo) 36:332-340.

Nesom, G.L. 2010. Overview of Liriope and Ophiopogon (Ruscaceae) naturalized and commonly cultivated in the USA. Phytoneuron 56:1-31.

Oinuma, T. 1944. Chromosome number of Ophiopogon planiscapus Nakai. Jap. J. Genet. 20:130-131 [in Japanese].

Oinuma, T. 1946. Karyotype analysis of Liriope and Ophiopogon. La Kromosomo 2:71-75 [in Japanese with English summary].

Oinuma, T. 1949. Further studies on chromosomes of Ophiopogonaceae. Jap. J. Genet. Suppl. 229-34 [in Japanese with English résumé].

Parris, J.K., T.G. Ranney, H.T. Knap, and W.V. Baird. 2010. Ploidy levels, relative genome sizes, and base pair composition in magnolia. J. Amer. Soc. Hort. Sci. 135:533-547.

Ranney, T.G. 2006. Polyploidy: From evolution to new plant development. Proc. Intern. Plant Propagators' Soc. 56:604-607.

Roy, S.C., S. Ghosh, and A. Chatterjee. 1988. A cytological survey of eastern Himalayan plants. II. Cell Chromosome Res. 11:93-97.

Rudall, P. 2000. Systematics of Ruscaceae/Convallariaceae: A combined morphological and molecular investigation. Bot. J. Linn. Soc. 134:73-92.

Sarkar, A.K., R. Datta, and M. Raychowdhury. 1974. In IOPB chromosome number reports XLVI. Taxon 23:801-812.

Sato, D. 1942. Karyotype alteration and phylogeny in Liliaceae and allied families. J. Jpn. Bot. 12:57-161.

Sen, S. 1973. Structural hybridity intra- and interspecific levels in Lilliales. Folia Biol. (Cracow) 21:183-197.

Sharma, A.K. and M. Chaudhuri. 1964. Cytological studies as an aid in assessing the status of Sanseviera, Ophiopogon, and Curculigo. Nucleus 7:43-58.
Sheriff, A. and B.K.S. Singh. 1975. Hexaploid wild populations of Ophiopogon intermedium from Shiradi Ghats, Karnataka State. Proc. Indian Sci. Congr. Assoc. 62:117.

Skinner, H.T. 1971. Some liriopogon comments. J. Royal Hort. Soc. 96:345-350.

Tamura, M.N. 1990. Studies on the genus Ophiopogon (Liliaceae) of Phu Kradung in Thailand. Acta Phytotax. Geobot. 41:1-6.

Tanaka, N. 2000. Taxonomic notes on Ophiopogon of South Asia VII. J. Jpn. Bot. 75:191-212.

Tanaka, N. 2001a. Taxonomic notes on Ophiopogon (Convallariaceae) of East Asia (I). J. J. Bot. 76:59-76.

Tanaka, N. 2001b. Taxonomic notes on Ophiopogon (Convallariaceae) of East Asia (II). J. Jpn. Bot. 76:151-165.

Tanaka, N. 2001c. Taxonomic notes on Ophiopogon (Convallariaceae) of East Asia (III). J. Jpn. Bot. 76:205-218.

Terasaka, O. and R. Tanaka. 1974. Cytological studies on the nuclear differentiation in microspore division of some angiosperms. Bot. Mag. Tokyo 87:209-217.

Thunberg, C.P. 1780. Convallaria japonica. November Act. Reg. Soc. Upsala 3:208.

Trueblood, C.E. 2009. An estimate of the commercial value of potentially invasive nursery crops grown in North Carolina, p. 63-75. In: An Invasive Species Assessment System for the North Carolina Horticultural Industry. MS thesis, North Carolina State University, Raleigh, NC.

Wang, G., Y. Meng, and Y. Yang. 2013. Karyological analyses of 33 species of the tribe Ophiopogoneae (Liliaceae) from Southwest China. J. Plant Res. 126:597-604.

Wang, K.W., X.Y. Ju, L. Zhang, W. Wang, and L.Q. Shen. 2012. A novel C27-steroidal glycoside sulfate from Liriope graminifolia. Yao Xue Xue Bao 47:619-623.

Wang, S.-F. and J.-M. Xu. 1990. Report on karyotypes of Smilacina tatsienensis and Ophiopogon japonicus. Acta Phytotaxonomica Sinica 28:207-210.

Westfall, J.J. 1950. Aneuploidy in Liriope muscari Bailey. Amer. J. Bot. 37:667.

Wu, T., Y. Wang, and B. Yu. 1998. Classification of four species of plant genus Liriope (Liriope Lour.) using RAPD. Chin. Tradit. Herbal Drugs 29:37-40.

Yamashita, J. and M.N. Tamura. 2001. Karyotype analysis of six species of the genus Ophiopogon (Convallariaceae-Ophiopogoneae). J. Jpn. Bot. 76:100-119

Yang, Y.-P., H. Li, X.-Z. Liu, and K. Kondo. 1990. Karyotype study on the genus Ophiopogon in Yunnan. Acta Bot. Yunnan. Suppl. 394-102 [in Chinese with English abstract].

Yu, B.-Y., S.-X. Qiu, K. Zaw, G.-J. Xu, Y. Hirai, J. Shoji, H.S. Fong, and A. Douglas. 1996. Steroidal glycosides from the subterranean parts of Liriope spicata var. prolifera. Phytochem. 43:201-206.

Zhang, D.M. 1998. Systematics of tribe Ophiopogoneae (Liliaceae s.1.) with special reference to karyotypes and chromosomal evolution. Cathaya 10:1-154.

Zhou, Q., J. Zhou, J. Chen, and X. Wang. 2009. Karyotype analysis of medicinal plant Liriope spicata var. prolific. Biologia 64:680-683. 